\title{
Clip Choledocholithiasis after Laparoscopic Cholecystectomy
}

Therapeutic biliary endoscopy has been widely used to manage bile duct stones prior to, during, or after laparoscopic cholecystectomy and to treat complications of the procedure [1]. Since laparoscopic cholecystectomy came into widespread use, there have been reports on migration of the clips used to close the cystic duct or occlude the cystic artery [2,3]. There have been cases of direct migration through the papilla causing cholangitis, and of the development of choledocholithiasis [4$6]$. The present report describes a case of choledocholithiasis caused by the migration of two clips, probably from the cystic duct, which served as a nucleus for the formation of the stone.

The patient was a 52-year-old woman who had undergone laparoscopic cholecystectomy for acute cholecystitis 7 months previously. She presented with a history of a recent onset of pain in the right upper quadrant, radiating to the back. Laboratory values showed elevated bilirubin $(2.16 \mathrm{mg} / \mathrm{dl})$, alkaline phosphatase (756 U/1), and alanine aminotransferase (200 U/1). Ultrasonography showed a dilated bile duct $(9 \mathrm{~mm})$, but did not reveal any stones.

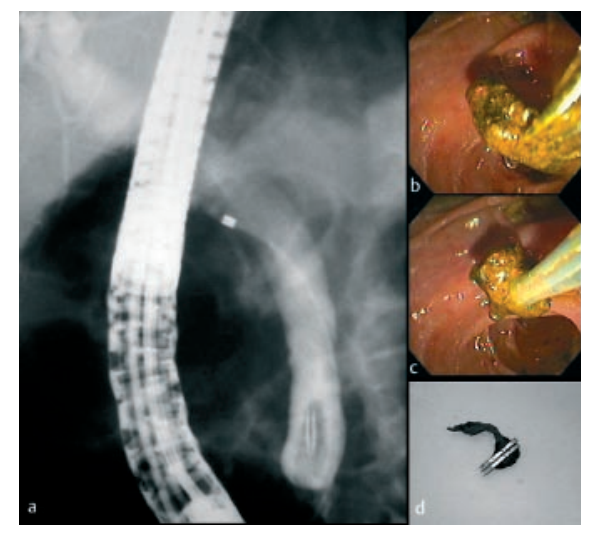

Figure 1 a ERCP showing the stone containing the clips. b, c The stone after extraction from the bile duct. The tips of the clips can be seen in $\mathbf{b}$. $\mathbf{d}$ The appearance of the clips after the biliary sludge surrounding them had been cleaned off.
Endoscopic retrograde cholangiopancreatography (ERCP) was carried out. A previous radiograph had shown two clips in the right upper quadrant (Figure 2a). Once the bile duct had been cannulated, a defect was seen in the distal bile duct, which corresponded to a stone with clips inside it. Papillotomy was carried out, and the stone was extracted. There were no other stones, and drainage was good. Two clips were found in the stone after removal (Figure 1). The final radiograph showed no clips in the right upper quadrant (Figure $\mathbf{2 b}$ ). The patient's post-ERCP course was uneventful and she was discharged.

\section{R. Angel' ${ }^{1}$, N. Abisambra² ${ }^{2}$ J. C. Marin ${ }^{3}$}

${ }^{1}$ Therapeutic Endoscopy Unit, Servicios Especiales de Salud (SES), Caldas Hospital, Manizales, Colombia

${ }^{2}$ National Cancer Institute, Bogotá, Colombia

${ }^{3}$ Dept. of Surgery, Caldas University, Manizales, Colombia.

\section{References}

${ }^{1}$ Shah SK, Mutignani M, Costamagna G. Therapeutic biliary endoscopy. Endoscopy 2002; 34: $43-53$

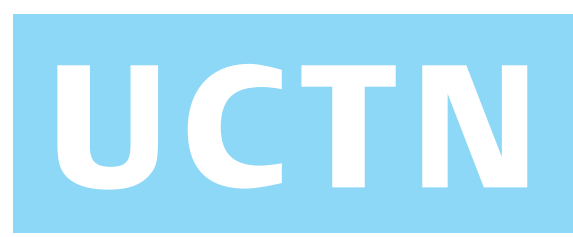

${ }^{2}$ Matsuura T, Kanisawa Y, Saito T et al. Migration of "endo-clips" into common bile duct after laparoscopic cholecystectomy. Lancet 1992; 340: 306

${ }^{3}$ Herline AF, Fisk JM, Debelak JP et al. Surgical clips: a cause of late recurrent gallstones. Am Surg 1998; 64: 845-848

${ }^{4}$ Martinez J, Combs W, Brady PG. Surgical clips as a nidus for biliary stone formation: diagnosis and therapy. Am J Gastroenterol 1995; 90: 1521 - 1524

${ }^{5}$ Venu RP, Brown RD, Rosenthal GR. An impacted metallic clip at the ampulla causing ascending cholangitis. Gastrointest Endosc 1997; 45: 435-436

${ }^{6}$ Petersen JM. Surgical clip choledocholithiasis. Gastrointest Endosc 2002; 56: 113

\section{Corresponding Author}

\section{R. Angel, M.D.}

Therapeutic Endoscopy Unit

Servicios Especiales de Salud (SES)

Caldas Hospital

Apartado Aéreo 2655

Manizales

Colombia

Fax: $\quad$ +57-68-811680

E-mail: rangelma@telesat.com.co

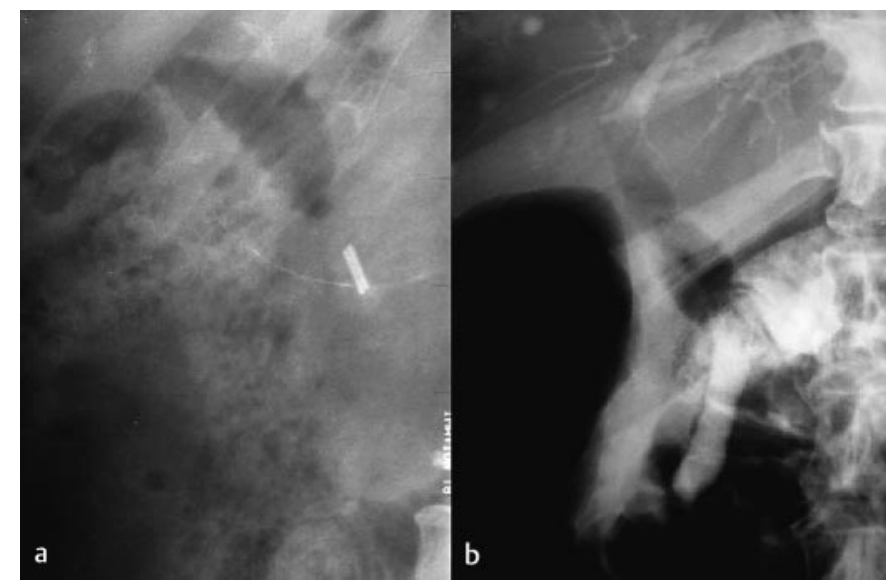

Figure 2 a Initial radiograph. The clips are visible below the 12th rib. b Final radiography after completion of the ERCP; no clips are visible. 